tigations about systems with non-circular cross-section.

A considerably increased effort on pulsed systems was noted. First, the generation of dense and hot plasma by intense laser beams may be mentioned here, where the possibility of using the laser light also for compressing and partially confining the plasma is now under discussion. In parallel, work is being pursued on the use of relativistic electron beams and rapid compression. In the field of plasma focus, the use of refined diagnostics has led to a better understanding of the underlying physics.

New results were reported on the plasma behaviour in mirror machines and on plasma instabilities and turbulence in general. In the latter field, a combined effort, experimental, nume- rical and computational, is being made now to reach a better understanding of the nonlinear phenomena involved and the related transport properties of the plasma. The results reported indicate that weak turbulence theory, whereas it provides good qualitative insight, is quantitatively unsatisfactory even at fairly low turbulence levels.

The success of the Conference was largely due to T. Consoli and E. Canobbio, and the Grenoble Organizing Committee, who prepared the meeting excellently and ran it smoothly. Financial help by the Commissariat à l'Energie Atomique, Paris, and the Commission of the European Communities, Brussels, is gratefully acknowledged.

F. Engelmann

\title{
Selected Problems in Magnetism
}

\section{Bochum, Fed. Rep. of Germany, 25-28 July 1972}

The Magnetism Section of the Condensed Matter Division of EPS held its inaugural meeting in Bochum, 25-28 July 1972. There were about 200 participants from 17 European and some non-European countries.

The topics and details of the programme were determined by an international programme committee comprising J. Als-Nielsen (Denmark), G. Heber (German Dem. Rep.), S. Krupicka (CSSR), S. Methfessel (Fed. Rep. of Germany), A.R. Miedema ( $\mathrm{Ne}$ therlands), S. Shtrikman (Israel), D. Wagner (Fed. Rep. of Germany), and E.P. Wohlfarth (U.K.). The decisions on topics and speakers to be invited were made after a call for papers which was submitted to the national representatives of the Magnetism Section. In this way, it was hoped, a survey of the current activities in Europe could be given and presented at the conference. Out of a large number of proposals, the following were chosen as topics of the conference as being of the greatest general interest :

Critical phenomena,

Hubbard model,

Itinerant magnetism,

Localized moments,

Magnetic resonance,

Magneto-optics,

Rare earths,

Symmetries and structures.
The sessions of the meeting were subdivided into general sessions, which were held in the morning, and workshop sessions, which were held in the afternoon. The general sessions contained talks mostly surveying a specific field which was connected with the subject of a workshop session. There were three parallel workshop sessions every day, each session devoted to a different topic. In these sessions, there was ample time for discussions or short communications by participants, and sometimes heated discussions on controversial subjets took place.

For those participating, it was a particular pleasure to welcome L.F. Bates (Nottingham) and E.I. Kondorsky (Moscow) who attended the conference as guests of honour and who delivered talks on 'A link between past and present in European magnetism' and 'On the band theory of magnetic anisotropy of $\mathrm{Ni}$ and dilute $\mathrm{Ni}$ alloys', respectively.

As an inaugural meeting of a Section of an EPS Specialized Division the conference seems to have succeeded admirably in bringing together Europeans practising one of the oldest of the physical sciences, which is today perhaps more topical than ever. The Section is grateful to all those who helped to make this conference the success it was.

E.P. Wohlfarth, D. Wagner
Letter

to the Editor

\section{References}

Sir,

I was interested to see that the EPS Advisory Committee on Publications has prepared a Europhysics Style Manual, the draft of which was published in Europhysics News vol. 3, no. 4, May 1972. While most of this appears useful and unobjectionable, there are two points on the presentation of references which I should like to raise as a physicist working as an information scientist.

Firstly, it is now accepted practice to give the final as well as the initial page number when referring to an article in a periodical. This practice indicates whether the item is a substantial article or a brief note, and it is very helpful in deciding whether to borrow the periodical or request a photocopy if it is not available in one's own library.

Secondly, it is much more useful if titles of articles are quoted as well as the periodicals in which they appear. Much waste of time and expense is often incurred in looking up and obtaining papers quoted in a list of references, only to find that the topic of interest is a very subsidiary part of their content. Now that authors are being encouraged to write informative titles, it seems only reasonable that these titles should be given to help readers judge the relevance of the papers quoted. The increased usefulness would easily outweigh the small additional space taken up.

The inclusion of titles and final page numbers is in accordance with the relevant ISO Recommendation ( $R 77$; Bibliographical references - essential elements, 1958) and the British Standard (BS 1629: 1950: Bibliographical references), and is the form illustrated by the Royal Society in its General Notes on the Preparation of Scientific Papers (2nd ed., 1965).

It would be a pity if EPS were to produce a style manual which leads authors and publishers to depart from these recommendations.
L.D. Will,
The City University,
St. John Street,
London ECIV 4PB.

Readers are invited to submit 'Letters to the Editor' either on items published in Europhysics News or on matters which would interest all European physicists. 